Arq. Bras. Med. Vet. Zootec., v.68, n.4, p.1053-1061, 2016

\title{
Determinantes de lucratividade em fazendas leiteiras de Minas Gerais
}

[Determinants of profitability in Minas Gerais dairy farms]

\author{
J.C. Resende ${ }^{1}$, A.F. Freitas ${ }^{1}$, R.A.N. Pereira ${ }^{2}$, H.C.M. Silva ${ }^{3}$, M.N. Pereira ${ }^{4} *$ \\ ${ }^{1}$ Embrapa Gado de Leite - Juiz de Fora, MG \\ ${ }^{2}$ Empresa de Pesquisa Agropecuária de Minas Gerais-URESM, Lavras, MG \\ ${ }^{3}$ Universidade Federal de Minas Gerais-EV-UFMG-Belo Horizonte, MG \\ ${ }^{4}$ Universidade Federal de Lavras-Lavras, MG
}

\begin{abstract}
RESUMO
Identificaram-se quais indicadores de desempenho determinam a variação na lucratividade de 159 fazendas da região Triângulo Mineiro-Alto Paranaíba de Minas Gerais. A lucratividade foi mensurada pela renda líquida anual (RL), RL sobre o valor dos bens e RL sobre a renda bruta. Cento e dezenove fazendas com lucratividade positiva produziram mais leite por mão de obra e por vaca, tinham maior proporção de vacas em lactação e maior proporção de custo com concentrados, custo com mão de obra com menor proporção do custo de produção e menor relação entre o custo com mão de obra e o custo com concentrados do que as 40 fazendas com lucratividade negativa $(\mathrm{P}<0,01)$. A análise de componentes principais mostrou que os principais determinantes da variação na lucratividade entre fazendas foram: relação entre o custo com mão de obra e o com concentrados, custo de mão de obra por litro de leite, produção de leite por mão de obra, produção de leite por vaca e proporção de vacas lactantes no rebanho. Maior lucratividade foi associada ao uso mais eficiente da mão de obra, ao maior investimento em concentrados e ao ganho na produção por vaca.
\end{abstract}

Palavras-chave: pecuária leiteira, contabilidade, indicadores de desempenho, Brasil

\begin{abstract}
We identified which performance indicators determined the variation in profitability of 159 farms of the Triângulo Mineiro-Alto Paranaíba region of Minas Gerais. Profitability was measured by annual net income (RL), RL over assets value, and RL over gross income. The 119 farms with positive profitability produced more milk per labor and per cow, had a greater proportion of lactating cows in the herd, had concentrates cost as a greater proportion and labor cost as a smaller proportion of the production cost, and had smaller ratio of labor cost to concentrates cost than the 40 farms with negative profitability $(P<0.01)$. Principal component analysis showed that the key determinants of profitability variation among farms were: The ratio of labor cost to concentrates cost, labor cost per liter of milk, milk yield per labor, milk yield per cow, and the proportion of lactating cows in the herd. Increased profitability was associated with more efficient labor usage, the result of larger investment in concentrates and greater yield per cow.
\end{abstract}

Keywords: dairy farming, accounting, performance indicators, Brazil

\section{INTRODUÇÃO}

A lucratividade da atividade leiteira, definida como a eficiência do negócio de gerar lucro ou renda líquida (RL), é relacionada ao efeito isolado e à interação entre variáveis, entre elas as inerentes à tecnologia de produção, às condições de mercado, à localização geográfica e ao

Recebido em 25 de fevereiro de 2015

Aceito em 25 de agosto de 2015

*Autor para correspondência (corresponding author)

E-mail: mpereira@dzo.ufla.br clima (Juszczyk, 2005). A lucratividade pode ser avaliada, entre muitos outros, por três indicadores: renda líquida (RL) - calculada pela diferença entre a renda bruta total (RBT) e o custo total (CT) -, taxa de retorno sobre os bens (TRB) - calculada pela divisão da RL pelo valor dos bens de produção - e margem de lucro (ML), dada pela relação entre RL e RBT, que 
representa a proporção da renda que permaneceu na fazenda após remunerar os itens considerados nos custos de produção (Kay e Edwards, 1999).

Conhecer índices da atividade que são importantes como determinantes da lucratividade tem uso prático, principalmente em propriedades com escrituração contábil falha ou inexistente. Definir metas de eficiência com base em indicadores de desempenho chave (IDC) é de implantação e atualização mais simples que o monitoramento direto de indicadores de lucratividade, pois os últimos requerem a adoção rotineira de práticas contábeis metodologicamente complexas (Schuh, 1976; Frank, 1991). Fuhrmann (2006) sugeriu que a lucratividade da atividade leiteira pode ser monitorada de forma indireta por meio dos IDC, basicamente um conjunto de poucos índices, porém de fácil medição e atualização, estratégicos para monitorar de maneira simples a lucratividade. Os IDC são medidas estratégicas da atividade que, mesmo desconhecendo os custos totais e as margens de rentabilidade, em conjunto, expressam com aproximação a lucratividade do empreendimento.

Hansen et al. (2005) estudaram 27 indicadores da produção de leite em fazendas da Noruega e identificaram que a despesa com concentrados e a diferença entre a renda bruta total e o custo com alimentação foram os principais determinantes da lucratividade. Haden e Johnson (1989) estudaram o efeito de 10 indicadores sobre o desempenho econômico de fazendas de leite do Tennessee, EUA. Produção por vaca e preço do leite tiveram maior impacto positivo sobre o resultado econômico, enquanto despesas com forragens e mão de obra, maior efeito negativo. Em fazendas do Wisconsin, EUA, os índices que mais se correlacionaram com a lucratividade foram a participação da mão de obra familiar no negócio, o manejo alimentar adotado e a frequência diária de ordenhas (Cabrera et al., 2008). Na Polônia, Kamieniecki et al. (1999) observaram que os principais determinantes de lucratividade nas fazendas de leite foram a qualidade do solo e a proporção de pastagem na área das fazendas. No Brasil, encontram-se estudos sobre a rentabilidade de fazendas de leite, mas a definição de IDCs não tem sido prevalente.
Esta pesquisa foi realizada com o objetivo de definir quais índices de desempenho foram os principais determinantes de lucratividade (RL, TRB e ML) em fazendas de leite da região Triângulo Mineiro-Alto Paranaíba de Minas Gerais.

\section{MATERIAL E MÉTODOS}

A amostra foi composta por 159 fazendas, que adotavam consultoria técnica por metodologia do projeto Educampo (Serviço..., 2009), entre agosto de 2007 e julho de 2008. A descrição das fazendas, da coleta de dados e de seus índices zootécnicos e econômicos foi feita por Resende et al. (2015).

Os seguintes índices foram avaliados: 1) leite produzido (L/dia); 2) área ocupada com leite (ha); 3) mão de obra contratada (funcionários); 4) vacas em lactação (cabeças); 5) vacas adultas (cabeças); 6) gado jovem (cabeças); 7) rebanho total (cabeças); 8) vacas secas/vacas adultas (\%); 9) vacas em lactação/rebanho total $(\%)$; 10) vacas em lactação/vacas secas; 11) gado jovem/rebanho total (\%); 12) vacas em lactação/área (cabeças/ha); 13) vacas adultas/área (cabeças/ha); 14) rebanho total/área (cabeças/ha); 15) leite/vaca em lactação (L/ano); 16) leite/vaca adulta (L/ano); 17) leite/mão de obra contratada (L/dh/ano); 18) leite/área (L/ha/ano); 19) valor dos bens sem terra (R\$); 20) valor dos bens com a terra $(\mathrm{R} \$) ; 21)$ valor da terra $(\mathrm{R} \$ / \mathrm{ha}) ; 22)$ valor da terra/valor dos bens com a terra $(\%) ; 23$ ) custo de mão de obra contratada (R\$/L); 24) custo de concentrados $(\mathrm{R} \$ / \mathrm{L}) ; 25)$ custo de concentrados/custo total $(\%) ; 26)$ custo de mão de obra/custo total $(\%) ; 27)$ custo de mão de obra/custo de concentrados; 28) custo total médio (R\$/L); 29) preço do leite $(\mathrm{R} \$ / \mathrm{L}) ; 30)$ renda bruta do leite ( $\mathrm{R} \$ / \mathrm{ano}) ; 31$ ) renda bruta total (R\$/ano); 32) renda bruta total por litro produzido $(\mathrm{R} \$ / \mathrm{L}) ; 33)$ renda líquida/mão de obra (R\$/ano); 34) renda líquida/vaca em lactação (R\$/ano); 35) renda líquida/vaca adulta (R $\$$ /ano); 36) renda bruta do leite/renda bruta total $(\%) ; 37)$ renda líquida/área (R\$/ha/ano); 38) distância da cidade (km) e 39) idade do proprietário (anos).

Três indicadores de lucratividade foram considerados como variáveis dependentes nas metodologias estatísticas: RL, TRB e ML. Para o cálculo desses indicadores, o custo de produção foi estimado considerando ou não os juros sobre o capital investido na produção (Resende et al., 
2015). Dois procedimentos foram utilizados para identificar quais índices seriam os principais determinantes da lucratividade das fazendas: análise de grupos (Alves et al., 2006) e análise de componentes principais (Jolliffe, 2002).

$\mathrm{Na}$ análise de grupos, as fazendas foram distribuídas em fazendas de lucratividade negativa $(\mathrm{RL}<0)$ e fazendas de lucratividade positiva $(R L>0)$. Os valores dos índices de cada grupo foram, então, comparados e ordenados pelo valor de probabilidade gerado pelo teste $\mathrm{t}$ de Student. Os 39 índices mencionados anteriormente foram analisados nessa fase.

A análise de componentes principais foi rodada pelo procedimento PRINCOMP do programa SAS, tendo, inicialmente, sido feita a padronização dos dados (Moita Neto e Moita, 1998), dividindo-se os valores de cada índice pela respectiva média. Quando houve correlação acima de 0,70 entre dois ou mais índices, para evitar o efeito de multicolinearidade (Chatterjee e Price, 1991), apenas aquele mais correlacionado, em média, com os três indicadores de lucratividade foi considerado.

Para a seleção dos componentes principais relevantes para a análise, seguiu-se o critério sugerido por Jolliffe (2002) de utilizar apenas aqueles que apresentassem autovalores maiores que 0,7, descartando-se os demais. Equações de regressão linear foram geradas, nas quais os componentes principais foram selecionados como variáveis independentes, e os três indicadores de lucratividade como variáveis dependentes.

\section{RESULTADOS E DISCUSSÃO}

A inclusão ou não dos juros sobre o capital depreciável no cálculo do custo de produção originou dois valores para as variáveis econômicas determinantes da lucratividade (Resende et al., 2015). Entretanto, a correlação entre os valores das variáveis contábeis obtidas com ou sem a consideração dos juros variou de 0,94 a 0,99 . Por isso, optou-se por adotar os valores de lucratividade obtidos utilizando-se os juros nos cálculos, por ser essa metodologia coerente com o procedimento adotado pelas federações da agricultura de Minas Gerais (Federação..., 2006) e de Goiás (Federação..., 2009) e a mais recomendada na teoria econômica (Barros, 1948; Schuh, 1976; Frank, 1991).

Do total estudado, 40 fazendas (25\%) apresentaram lucratividade negativa, e 119 positiva (Tab. 1). A RL representa um valor residual a ser utilizado para remunerar os fatores de produção não imputados nos custos totais (Matsunaga et al., 1976). Na presente análise, esses fatores foram a mão de obra familiar e o custo de oportunidade do empresário.

Tabela 1. Indicadores de lucratividade em fazendas produtoras de leite da mesorregião Triângulo Mineiro-Alto Paranaíba, MG, com renda líquida anual negativa $(\mathrm{RL}<0)$ ou positiva $(\mathrm{RL}>0)$

\begin{tabular}{lll}
\hline & $\mathrm{RL}<0$ & $\mathrm{RL}>0$ \\
\hline Fazendas & 40 & 119 \\
Renda líquida (R\$/ano) & $-31122,55$ & 54340,73 \\
Renda líquida/renda bruta (\%) & $-19,3$ & 18,1 \\
Renda líquida/valor dos bens (\%/ano) & $-4,4$ & 7,8 \\
\hline
\end{tabular}

Apenas $28 \%$ dos indicadores avaliados foram significativamente diferentes $(\mathrm{P}<0,01)$ entre fazendas com RL positiva e negativa (Tab. 2). Fazendas com RL positiva tiveram maior produção de leite por unidade de mão de obra e por vaca e maior proporção no rebanho de vacas em lactação do que fazendas com RL negativa. Fazendas com resíduo positivo tiveram maior participação do custo de concentrados e participação mais baixa do custo de mão de obra no custo total (Tab. 2). Os dados sugerem que investir em alimentos concentrados para ter alta produção por vaca e, consequentemente, diluir o custo de mão de obra entre o total de custos foi uma estratégia efetiva. As fazendas com eficiência financeira positiva tiveram menor custo total médio e maior preço do leite, variáveis que entram diretamente nas equações de cálculo dos indicadores de lucratividade. Entretanto, definir metas de eficiência regional ou para grupos individuais de fazendas com base nesses valores pode ser pouco efetivo, já que tanto o preço quanto o custo resultam do conjunto de todos os fatores envolvidos na produção, tendo caráter extremamente multifatorial. 
Indicadores de tamanho da fazenda ou do negócio ou a idade do produtor não diferiram entre fazendas agrupadas de acordo com a renda líquida (Tab. 2). A taxa de lotação animal e a produção por área, normalmente consideradas metas zootécnicas importantes em sistemas de produção de leite, não diferiram entre esses grupos de fazendas. A intensificação ou não do fator terra não foi um grande determinante de lucratividade, coerente aos baixos valores de produtividade da terra nesse grupo de fazendas (Resende et al., 2015), em que disponibilidade de terra não foi um fator limitante da produção. A RL por vaca, por mão de obra ou por área também não diferiu entre os grupos de fazendas.

Tabela 2. Indicadores zootécnicos e econômicos em fazendas produtoras de leite da mesorregião Triângulo Mineiro-Alto Paranaíba, MG, com renda líquida anual negativa $(\mathrm{RL}<0)$ ou positiva $(\mathrm{RL}>0)$

\begin{tabular}{|c|c|c|c|}
\hline & $\mathrm{RL}<0$ & $\mathrm{RL}>0$ & $P$ \\
\hline Custo total médio $(\mathrm{R} \$ / \mathrm{L})$ & 1,19 & 0,83 & 0,000000 \\
\hline Custo de mão de obra contratada ( $\mathrm{R} \$ / \mathrm{L})$ & 0,15 & 0,08 & 0,000000 \\
\hline Custo de concentrados/custo total (\%) & 25,11 & 32,62 & 0,000001 \\
\hline Custo de mão de obra/custo total (\%) & 12,81 & 9,16 & 0,000071 \\
\hline Leite/mão de obra contratada (L/ano) & 79532 & 111346 & 0,000068 \\
\hline Leite/vaca adulta (L/ano) & 2729 & 3603 & 0,000125 \\
\hline Leite/vaca em lactação (L/ano) & 3860 & 4752 & 0,000411 \\
\hline Vacas secas/vacas adultas (\%) & 30,2 & 25,3 & 0,000945 \\
\hline Vacas em lactação/rebanho total (\%) & 32,7 & 37,2 & 0,001508 \\
\hline Vacas em lactação/vacas secas & 2,60 & 3,35 & 0,002447 \\
\hline Preço do leite $(\mathrm{R} \$ / \mathrm{L})$ & 0,82 & 0,86 & 0,004083 \\
\hline Custo de mão de obra/custo de concentrados & 0,51 & 0,37 & 0,078478 \\
\hline Renda bruta do leite/renda bruta total (\%) & 83,3 & 86,2 & 0,084449 \\
\hline Gado jovem/rebanho total $(\%)$ & 53,0 & 50,4 & 0,090225 \\
\hline Custo de concentrados $(\mathrm{R} \$ / \mathrm{L})$ & 0,29 & 0,27 & 0,096983 \\
\hline Leite/área (L/ano) & 2789 & 3516 & 0,144105 \\
\hline Mão de obra contratada & 2,9 & 2,5 & 0,294422 \\
\hline Leite produzido (L/d) & 671,7 & 802,5 & 0,305490 \\
\hline Valor dos bens sem terra $(\mathrm{R} \$)$ & 350925 & 319049 & 0,484987 \\
\hline Idade do proprietário (anos) & 51,6 & 50,3 & 0,525409 \\
\hline Rebanho total/área (/ha) & 2,04 & 1,91 & 0,527725 \\
\hline Vacas em lactação & 55,5 & 59,8 & 0,548731 \\
\hline Gado jovem & 92,3 & 85,9 & 0,578644 \\
\hline Renda bruta do leite (R\$/ano) & 231088 & 256065 & 0,589558 \\
\hline Renda bruta total (R\$/ano) ${ }^{1}$ & 1,00 & 1,01 & 0,590355 \\
\hline Renda líquida/mão de obra (R\$/ano) & 11305 & 13156 & 0,633231 \\
\hline Área ocupada com leite (ha) & 104,4 & 110,2 & 0,675817 \\
\hline Renda bruta total $(\mathrm{R} \$ / \mathrm{ano})^{1}$ & 271112 & 293016 & 0,682824 \\
\hline Vacas em lactação/área (/ha) & 0,68 & 0,71 & 0,683564 \\
\hline Distância da cidade $(\mathrm{km})$ & 28,3 & 27,1 & 0,691502 \\
\hline Renda líquida/vaca adulta (R\$/ano) & 361 & 404 & 0,733253 \\
\hline Rebanho total & 173 & 167 & 0,758205 \\
\hline Renda líquida/vaca em lactação (R $\$$ /ano) & 465 & 510 & 0,785846 \\
\hline Valor da terra (x R $\$ 1000,00 / h a)$ & 5,00 & 5,12 & 0,805643 \\
\hline Vacas adultas/área (/ha) & 0,97 & 0,95 & 0,817333 \\
\hline Renda líquida/área (R\$/ha/ano) & 348 & 380 & 0,822774 \\
\hline Valor da terra/valor dos bens (\%) & 56,9 & 56,3 & 0,828910 \\
\hline Valor dos bens $(\mathrm{R} \$)$ & 797344 & 802691 & 0,953055 \\
\hline Vacas adultas & 80,9 & 80,9 & 0,999460 \\
\hline
\end{tabular}

${ }^{1}$ Considera o valor do leite comercializado adicionado da renda oriunda da venda de animais e de produtos excedentes, como esterco e forragens. 
A análise de componentes principais (Tab. 3) considerou os seguintes índices: leite/vaca adulta (L/ano), vacas em lactação/vacas secas, leite/mão de obra contratada (L/dh/ano), preço do leite $(\mathrm{R} \$ / \mathrm{L})$, valor da terra/valor dos bens com terra (\%), renda bruta do leite/renda bruta total $(\%)$, custo de concentrados $(\mathrm{R} \$ / \mathrm{L})$, custo de mão de obra contratada ( $\mathrm{R} \$ \mathrm{~L})$, idade do proprietário (anos) e custo de mão de obra contratada/custo de concentrados. A correlação linear entre essas variáveis foi abaixo de 0,69 , mostrando a inexistência de multicolinearidade entre elas (Tab. 4). Apenas o componente principal 1 (CP1) resultou em autovalor maior que 0,7 (Jolliffe, 2002), portanto foi o único pertinente (Tab. 3). O CP1 explicou $64,4 \%$ da variabilidade nos dados.
A proporção e o valor de cada variável no CP1 (Tab. 5) permitiram confirmar as tendências obtidas na análise dos grupos de fazendas com lucratividade positiva ou negativa (Tab. 2). Variáveis que descrevem a eficiência de uso da mão de obra estiveram entre as três mais importantes, seguidas por produção de leite por vaca e pela relação entre o número de vacas lactantes e o número de vacas secas. $\mathrm{O}$ cenário macroeconômico favorável durante este estudo teoricamente favoreceu a adoção de tecnologias, em razão do preço recorde do leite pago aos produtores (Centro..., 2009). O relacionamento entre indicadores de desempenho e lucratividade em um cenário de preços baixos do leite pode diferir e merece avaliação, já que flutuações econômicas extremas são frequentes na indústria leiteira mundial (International..., 2009).

Tabela 3. Componentes principais (CP), autovalores e proporção individual e acumulada da variância explicada pelo CP em fazendas produtoras de leite da mesorregião Triângulo Mineiro-Alto Paranaíba, MG

\begin{tabular}{llll} 
& Autovalores & $\begin{array}{l}\text { Proporção da } \\
\text { variância no CP }\end{array}$ & $\begin{array}{l}\text { Proporção acumulada } \\
\text { da variância }\end{array}$ \\
\hline Componente principal 1 & 1,36010454 & 0,644 & 0,644 \\
Componente principal 2 & 0,28313821 & 0,134 & 0,776 \\
Componente principal 3 & 0,16716868 & 0,079 & 0,857 \\
Componente principal 4 & 0,10652196 & 0,050 & 0,908 \\
Componente principal 5 & 0,07284823 & 0,034 & 0,942 \\
Componente principal 6 & 0,04301442 & 0,020 & 0,962 \\
Componente principal 7 & 0,03601528 & 0,017 & 0,980 \\
Componente principal 8 & 0,02990997 & 0,014 & 0,994 \\
Componente principal 9 & 0,00832403 & 0,004 & 0,998 \\
Componente principal 10 & 0,00509546 & 0,002 & 1,0000 \\
\hline
\end{tabular}

Entretanto, o preço do leite, historicamente citado por produtores como a principal causa de insucesso na atividade leiteira (Federação..., 1996), foi a variável menos determinante da diferença na lucratividade entre fazendas, sendo majoritária no componente principal 10 (Tab. 5). O baixo impacto do preço do leite sobre a diferença em lucratividade pode ser explicado pela baixa variabilidade nessa variável entre fazendas (Resende et al., 2015). A renda bruta do leite como proporção da renda bruta total foi majoritária no componente principal 9 e, portanto, a penúltima em ordem de importância, mostrando que o negócio leite foi pouco afetado pelo fato de a fazenda ter ou não outras fontes de renda além do leite comercializado, principalmente venda de animais. Nessas fazendas, o direcionamento dos negócios para a venda de animais não foi mais lucrativo que negócios direcionados para a venda de leite, sendo o oposto também verdadeiro. A venda de leite representou $85,5 \pm 9,3 \%$ da renda bruta total dessas fazendas (Resende et al., 2015), indicando que o negócio majoritário foi a venda de leite.

Os coeficientes das regressões lineares que descreveram a variação nos indicadores de lucratividade por unidade de variação no CP1, estimado pelo valor de cada variável padronizado para a média (Intercepto $=1$ ), foram: $-0,59$ para a RL, $-0,80$ para a TRB e $-0,96$ para a ML. O indicador de lucratividade com resposta mais acentuada por unidade de mudança no CP1 foi a ML e o menos responsivo foi a RL. Na Tab. 6, são apresentados os valores dos coeficientes da regressão balanceados para o peso de cada variável no $\mathrm{CP} 1$ (Tab. 5). A média dos coeficientes enfatiza a importância de obter diluição do custo de mão de obra para a obtenção de alta lucratividade e sugere que a restrição da oferta de concentrados ao rebanho não seria uma rota eficaz. 
Tabela 4. Correlação linear entre as 10 variáveis selecionadas pela análise de componentes principais estimados de dados de fazendas produtoras de leite da mesorregião Triângulo Mineiro-Alto Paranaíba, MG

\begin{tabular}{|c|c|c|c|c|c|c|c|c|c|c|}
\hline Variável & 1 & 2 & 3 & 4 & 5 & 6 & 7 & 8 & 9 & 10 \\
\hline $\begin{array}{l}\text { Custo de mão de obra/custo de } \\
\text { concentrados }\end{array}$ & 1 & & & & & & & & & \\
\hline Custo de mão de obra contratada (R $\$ / L)$ & 0,69 & 1 & & & & & & & & \\
\hline Leite/mão de obra contratada (L/ano) & 0,39 & 0,44 & 1 & & & & & & & \\
\hline Leite/vaca adulta (L/ano) & 0,44 & 0,44 & 0,66 & 1 & & & & & & \\
\hline Vacas em lactação/vacas secas & 0,30 & 0,36 & 0,43 & 0,69 & 1 & & & & & \\
\hline Custo de concentrados (R $\$ / L)$ & 0,48 & 0,06 & 0,22 & 0,33 & 0,15 & 1 & & & & \\
\hline Valor da terra/valor dos bens $(\%)$ & 0,24 & 0,23 & 0,19 & 0,29 & 0,18 & 0,21 & 1 & & & \\
\hline $\begin{array}{l}\text { Renda bruta do leite/renda bruta total } \\
(\%)\end{array}$ & 0,38 & 0,33 & 0,48 & 0,49 & 0,33 & 0,18 & 0,14 & 1 & & \\
\hline Preço do leite (R $\$ / L)$ & 0,34 & 0,29 & 0,44 & 0,46 & 0,31 & 0,35 & 0,28 & 0,39 & 1 & \\
\hline Idade do proprietário (anos) & 0,07 & 0,17 & 0,09 & 0,11 & 0,04 & 0,01 & 0,16 & 0,01 & 0,08 & 1 \\
\hline
\end{tabular}

Valores negativos em itálico.

Tabela 5. Composição linear dos componentes principais (CP) obtidos de fazendas produtoras de leite da mesorregião Triângulo Mineiro-Alto Paranaíba, MG

\begin{tabular}{lcccccccccc}
\hline Variável & CP1 & CP2 & CP3 & CP4 & CP5 & CP6 & CP7 & CP8 & CP9 & CP10 \\
\hline $\begin{array}{l}\text { Custo de mão de obra/custo de } \\
\text { concentrados }\end{array}$ & 0,84 & 0,41 & 0,25 & 0,05 & 0,08 & 0,03 & 0,19 & 0,11 & 0,01 & 0,01 \\
Custo de mão de obra contratada & & & & & & & & & & \\
(R $\$$ L) & 0,41 & 0,16 & 0,82 & 0,04 & 0,05 & 0,03 & 0,30 & 0,16 & 0,03 & 0,01 \\
Leite/mão de obra contratada (L/ano) & 0,20 & 0,48 & 0,10 & 0,74 & 0,21 & 0,22 & 0,20 & 0,17 & 0,07 & 0,03 \\
Leite/vaca adulta (L/ano) & 0,19 & 0,47 & 0,22 & 0,01 & 0,13 & 0,40 & 0,35 & 0,62 & 0,11 & 0,00 \\
Vacas em lactação/vacas secas & 0,16 & 0,58 & 0,18 & 0,65 & 0,11 & 0,12 & 0,25 & 0,30 & 0,02 & 0,01 \\
Custo de concentrados (R\$/L) & 0,10 & 0,06 & 0,39 & 0,08 & 0,17 & 0,20 & 0,59 & 0,63 & 0,03 & 0,08 \\
Valor da terra/valor dos bens (\%) & 0,07 & 0,07 & 0,04 & 0,04 & 0,89 & 0,42 & 0,10 & 0,05 & 0,01 & 0,04 \\
Renda bruta do leite/renda bruta total & 0,04 & 0,06 & 0,01 & 0,04 & 0,02 & 0,01 & 0,06 & 0,07 & 0,92 & 0,37 \\
(\%) & 0,03 & 0,05 & 0,03 & 0,04 & 0,05 & 0,00 & 0,05 & 0,04 & 0,36 & 0,92 \\
Preço do leite (R $\$ / L)$ & 0,02 & 0,02 & 0,10 & 0,12 & 0,30 & 0,75 & 0,52 & 0,22 & 0,05 & 0,02 \\
Idade do proprietário (anos) & & & & & & & & & &
\end{tabular}

Valores negativos em itálico.

Tabela 6. Síntese da análise do componente principal 1 (CP1) sobre os indicadores de lucratividade renda líquida (RL), taxa de retorno sobre os bens (TRB) e margem de lucro (ML) obtidos em fazendas produtoras de leite da mesorregião Triângulo Mineiro-Alto Paranaíba, MG

\begin{tabular}{lllll}
\hline Indicador & $\mathrm{RL}$ & $\mathrm{TRB}$ & $\mathrm{ML}$ & Média \\
\hline Custo de mão de obra/custo de concentrados & 0,50 & 0,67 & 0,81 & 0,66 \\
Custo de mão de obra contratada (R\$/L) & 0,24 & 0,33 & 0,39 & 0,32 \\
Leite/mão de obra contratada (L/ano) & 0,12 & 0,16 & 0,19 & 0,16 \\
Leite/vaca adulta (L/ano) & 0,11 & 0,15 & 0,18 & 0,15 \\
Vacas em lactação/vacas secas & 0,09 & 0,13 & 0,15 & 0,13 \\
Custo de concentrados (R\$/L) & 0,06 & 0,08 & 0,10 & 0,08 \\
Valor da terra/valor dos bens (\%) & 0,04 & 0,06 & 0,07 & 0,06 \\
Renda bruta do leite/renda bruta total (\%) & 0,02 & 0,03 & 0,04 & 0,03 \\
Preço do leite (R\$/L) & 0,02 & 0,02 & 0,03 & 0,02 \\
Idade do proprietário (anos) & 0,01 & 0,02 & 0,02 & 0,02 \\
\hline Valo
\end{tabular}

Valores negativos em itálico.

O papel da produtividade da mão de obra como fator determinante da lucratividade é coerente com dados da literatura. Em fazendas de Minas Gerais, a produtividade da mão de obra contratada foi um dos três índices mais determinantes da lucratividade (Fassio et al., 2006). Esse índice também foi positivamente correlacionado com a taxa de remuneração do 
capital investido em fazendas de leite da Bahia (Schiffler et al., 1999; Lima, 2006). Com a tendência de elevação real dos salários (Centro..., 2009), gastos com mão de obra podem ser fator determinante cada vez mais significativo da lucratividade da atividade leiteira brasileira. Nesse cenário, pode crescer a importância da mão de obra familiar para a lucratividade da atividade, como relatado por Cabrera et al. (2008), em fazendas de leite de Wisconsin.

Entre os índices zootécnicos avaliados, três demonstraram ser os mais úteis para estimar a lucratividade das fazendas: produção de leite por mão de obra contratada, produção de leite por vaca adulta e a relação entre vacas em lactação e vacas secas. Como a correlação entre a produção de leite por vaca em lactação e a produção por vaca adulta foi 0,97 , o uso do primeiro indicador é adequado, já que a obtenção do dado envolve simplesmente a realização sistemática da prática de controle leiteiro. Contabilizar o gado adulto não produtivo pode ser impreciso em algumas fazendas, já que alguns animais, mesmo que existentes, podem não ser considerados unidades produtivas pelo produtor, como aqueles a serem descartados, por exemplo. Para o técnico que presta consultoria gerencial, contabilizar o rebanho adulto também é mais trabalhoso que contabilizar apenas o rebanho em lactação. Entre esses índices zootécnicos, a produção de leite por vaca em lactação é a de obtenção mais simples e, provavelmente, o dado de maior acurácia.

A correlação entre a produção de leite por vaca em lactação e a TRB foi positiva (Fig. 1). É importante enfatizar que a dispersão na produção por vaca e, provavelmente, nas práticas de manejo e composição genética dos rebanhos foi alta neste trabalho, comparativamente a dados internacionais publicados. Segundo os 18 consultores participantes desta pesquisa, $27 \%$ das fazendas estudadas não adotavam qualquer adubação de pastagens e $26 \%$ adotavam adubações razoáveis. Nos dados obtidos em 257 fazendas de Wisconsin (McCullough, 1994), a produção anual por vaca adulta variou de cerca de seis a $12 \mathrm{mil} \mathrm{kg}$, todas com produção leiteira média a alta, enquanto, neste trabalho, a amplitude foi de um a oito mil $\mathrm{kg}$ (Resende et $a l .$, 2015). Esses fatos sugerem que, entre distintos modelos tecnológicos de produção de leite, em média, a obtenção de maior produção por animal foi desejável.

Entretanto, apesar de a correlação entre a produção por vaca e a TRB ser positiva, o coeficiente de determinação foi baixo, refletindo a alta dispersão de pontos ao redor da reta de regressão (Fig. 1). Esse relacionamento foi idêntico ao observado em Wisconsin (McCullough, 1994). Nem sempre alta produtividade reflete em alta lucratividade, sendo o oposto também verdadeiro. A variabilidade nas decisões de manejo e nas práticas de gerenciamento entre fazendas com produção similar por vaca é uma explicação plausível para a alta dispersão na regressão (Noronha et al., 2001). Todavia, não existem dados que suportem um relacionamento negativo entre produtividade e lucratividade, evidenciando que produtores com maior produção por animal e que adotam práticas adequadas de manejo e administração obtêm maior eficiência financeira. Parece ser correto preconizar o aumento da produtividade por animal como meta nas fazendas deste estudo.

A menor relação entre o custo de mão de obra e o custo de alimentos concentrados nas fazendas mais eficientes em gerar lucro suporta o papel de diluição do trabalho humano dessa última tecnologia (Alves et al., 2006). Vale ressaltar que a planilha de custos utilizada neste trabalho não separou o uso de concentrados para a recria do uso para o rebanho em lactação (Resende et al., 2015). Deve ser considerado que vacas mais selecionadas para leite e capazes de maior produção por animal também são novilhas que requerem maior investimento em alimentos concentrados, do nascimento ao primeiro parto. Como foi irrisória a diferença na proporção de gado jovem em rebanhos com lucratividade positiva $(53 \%)$ ou negativa $(50,4 \%)$ (Tab. 2$)$, pode ser que a necessidade de concentrados para vacas em lactação por litro de leite produzido tenha sido menor nos rebanhos mais produtivos. Um avanço recomendável da metodologia contábil dessas fazendas seria a separação na contabilidade dos custos com recria dos custos com vacas em lactação (Tupy et al., 2000). Esse recurso pode gerar novas interpretações dos dados disponíveis quanto ao uso de concentrados, mas também de forragens e outros insumos usados em ambas as categorias animais. 


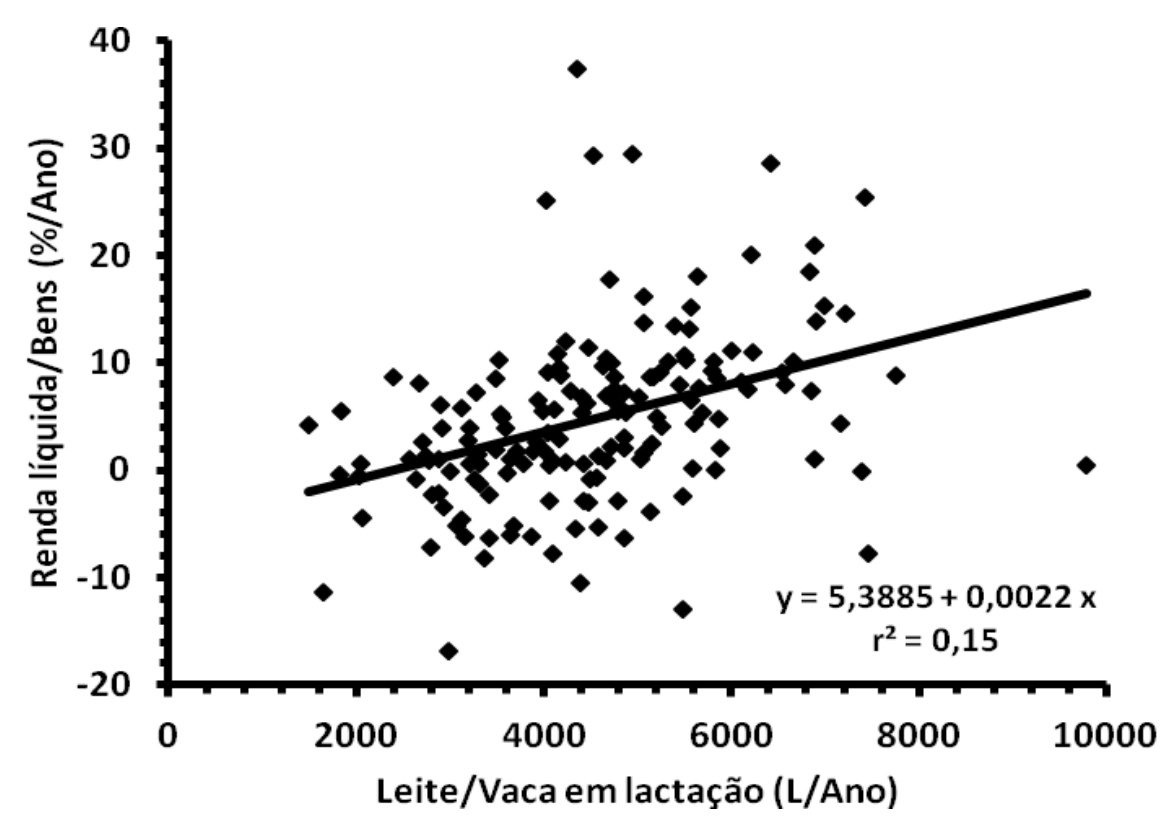

Figura 1. Relacionamento entre a produção de leite por vaca em lactação e a renda líquida anual sobre o valor dos bens em fazendas produtoras de leite da mesorregião Triângulo Mineiro-Alto Paranaíba, MG.

\section{CONCLUSÕES}

Nesse grupo de fazendas do oeste mineiro maior lucratividade foi associada a uso mais eficiente da mão de obra, determinado pelo uso de alimentos concentrados e maior produtividade por vaca. Rebanhos com maior proporção de animais em produção também foram mais eficientes. A obtenção de ganho em produção por vaca pode ser uma meta zootécnica plausível para direcionar a obtenção de ganho em lucratividade.

\section{REFERÊNCIAS}

ALVES, E.; SOUZA, G. S.; OLIVEIRA, C.A.V. Desempenho de estabelecimentos do Pronaf. Rev. Polít. Agríc., v.25, p.5-23, 2006.

BARROS, H. Economia agrária. Lisboa: Sá da Costa, 1948. v.1, 494p.

CABRERA, V.E.; SOLIS, D.; CORRAL, J.D. The effect of traditional practices in the efficiency of dairy farms in Wisconsin. Madison: University of Wisconsin, 2008. Disponível em: $<$ http://ageconsearch.umn.edu/ bitstream/55373/2/VC.DS.JC.SAEA.2010.pdf>. Acessado em: 20 dez. 2009.
CHATTERJEE, S.; PRICE, B. Regression analysis by example. New York: J. Wiley, 1991. 278p.

DIAGNÓSTICO da cadeia produtiva do leite de Goiás. Goiânia: Federação de Agricultura do Estado de Goiás, 2009. 64p.

DIAGNÓSTICO da pecuária leiteira do estado de Minas Gerais em 2005: relatório de pesquisa. Belo Horizonte: Federação de Agricultura do Estado de Minas Gerais, 2006. 156p.

DIAGNÓSTICO da pecuária leiteira do estado de Minas Gerais. Belo Horizonte: Federação de Agricultura do Estado de Minas Gerais, 1996. $2 \mathrm{v}$.

FASSIO, L.H.; REIS, R.P.; GERALDO, L.G. Desempenho técnico e econômico da atividade leiteira em Minas Gerais. Ciênc. Agrotec., v.30, p.1154-1161, 2006.

FOR a better understanding of milk production world-wide. Kiel: IFCN Dairy Research Center, 2009. 206p.

FRANK, R.H. Microeconomics and behavior. New York: McGraw-Hill, 1991. 694 p. 
FUHRMANN, T. Managing the dairy farm: key performance indicators. WCDS Adv. Dairy Technol., v.18, p.3-8, 2006. Disponível em: <http://www.wcds.afns.ualberta.ca/Proceedings/ 2006/Manuscripts/Fuhrmann.pdf> Acessado em: 7 nov. 2009.

HADEN, K.L.; JOHNSON, L.A. Factors which contribute to the financial performance of selected Tennessee dairies. Southern J. Agric. Econ., v.21, p.105-112, 1989.

HANSEN, B.G.; STOKSTAD, G.; HEGRENES, A. et al. Key performance indicators on dairy farms. J. Int. Farm Manag., v.3,p.1-15, 2005.

JOLLIFFE, I.T. Principal component analysis. New York: Springer, 2002. 487p.

JUSZCZYK, S. Milk production profitability: multiple regression analysis. Electr. J. Polish Agric. Univ., v.8, 2005. Disponível em: <http://www.ejpau.media.pl/volume8/issue4/art46.html>. Acessado em: 23 set. 2009.

KAMIENIECKI, K; GNYP, J; TRAUTMAN, J. Technical and economic characteristics of dairy farms in Central-East Poland. Livestock Prod. Sci., v.61, p.301-306, 1999.

KAY, R.D.; EDWARDS, W.M. Farm management. 4.ed., Boston: WCB McGraw-Hill, 1999. 494p.

LIMA, A.L.R. Eficiência produtiva e econômica da atividade leiteira em Minas Gerais. 2006. 65f. Dissertação (Mestrado em Administração) Universidade Federal de Lavras, Lavras, MG.

MATSUNAGA, M.; BEMELMANS, P.F.; TOLEDO, P.E.N. et al. Metodologia de custo de produção utilizada pelo IEA. Agric. São Paulo, v.23, p.123-139, 1976.

McCULLOUGH, D. Production-profit tie needs more study. Hoard's Dairyman, v.10, p.615, 1994.
MOITA NETO, J.M.; MOITA, G.C. Uma introdução à análise exploratória de dados multivariados. Rev. Quím. Nova, v.21, 1998. Disponível em: <http://www.scielo.br/ scielo.php?pid=S010040421998000400016\&scri pt=sci_arttext\&tlng=e\#fig1 $>$. Acessado em: 28 nov. 2009.

NORONHA, J.F.; NUNES, C.L.M.; GERALDINE, D.G. et al. Análise da rentabilidade da atividade leiteira no Estado de Goiás. Goiânia: UFG, 2001. 106p.

PREÇOS ainda resistem ao aumento de produção. Bol. Leite, v.15, p.2-3, 2009. Disponível em: <http://www.cepea.esalq.usp.br/ leite/>. Acessado em: 28 out. 2009. PROJETO Educampo. Belo Horizonte: Serviço Brasileiro de Apoio às Micro e Pequenas Empresas, 2008. Disponível em: <http://www.cpdeducampo. com.br/novosite/EducampoHistorico.htm>.

Acessado em: 9 set. 2009.

RESENDE, J.C.; PEREIRA, R.A.N.; PEREIRA, M.N. Indicadores de desempenho de fazendas leiteiras de Minas Gerais. Arq. Bras. Med. Vet. Zootec., 2015 - em submissão

SCHIFFLER, E.A.; MÂNCIO, A.B.; GOMES, S.T. et al. Efeito da escala de produção nos resultados econômicos da produção de leite B no Estado de São Paulo, Rev. Bras. Zootec., v.28, p.425-431, 1999.

SCHUH, G. E. Considerações teóricas sobre custos de produção na agricultura. Agric. São Paulo, v.23, p.97-121, 1976.

TUPY, O.; ALVES, E.R.A.; ESTEVES, S.N.; SCHIFFLER, E.A. Método para controle $e$ análise de custo de produção de leite. São Carlos: Embrapa Pecuária Sudeste, 2000. 35p. (Embrapa Pecuária Sudeste. Circular Técnica, 26). 